\title{
Wetenschappelijke Tijdingen
}

Overzicht van de 53ste jaargang (januari - december 1994)

\section{Bijdragen}

Asma, F.

Vlaamse strijd en mythevorming bij Marnix Gijsen. Boeva, L.

De sociale taalgrens in Vlaanderen en de reactie van de

Vlaamse Beweging en de Sociale Beweging (1830-1914).

De Smet, J.

- "Een paradijselijke natie". Het Baskenlandbeeld van een aantal na-oorlogse Vlaams-nationalisten.

- Het Vlaams steuncomité voor Baskische schooltjes.

De Wever, B.

"Rebellen" aan het Oostfront. De politieke moeilijk-

heden bij de Vlaamse Oostfronters. (Eerste deel) HANOT, L.M.

De pangermanist Ignaz Kuranda en Vlaanderen. IPEMA, J.

Alfred Toepfer - Nederduitser, Pan-Germaan of

Groot-Nederlander?

LAROY, P.

Het Willemsfonds en het Activisme.

LUYCKX, D.

Adelfons Henderickx en het activisme in Antwerpen

tijdens de Eerste Wereldoorlog - I: In 1914.

Roose, F.

Een rechtzetting.

VANACKer, D.

De jonge Minnaert.

VAN DEN BERG, J.J.

"Dietsland Houzee!"

De NSB en Vlaanderen 1940-1944. (Eerste deel)

Van Hees, P.

De familie Pieck en René de Clerq. Enkele opmerkingen naar aanleiding van het Dagboek van A.F. Pieck. 
Van Hoorick, K.

- De "humanitaire" kant van het activisme: de vereniging Volksopbeuring te Mechelen.

- De activistische achterban te Mechelen.

Verdoodt, F.-J.

Filmologie en historiografie in Vlaanderen. De Daensfilm:

historische bron of bron voor historische kennis? WILS, L.

- De aanloopperiode van Gaston Eyskens.

- Vlaams-nationalisme en Nieuwe Orde.

- Vijftig jaar geleden overleed Kamiel Van Caeneghem:

De grondlegger van een flamingantische volksbeweging.

\section{Nieuwe Uitgaven}

Baute, T. en Deprez, A.

Onze Vlag 1884. Ons Vaderland 1888-1889.

Land en Volk 1890-1896, Gent, Cultureel

Documentatiecentrum, 1993. (L. WILS)

Groeneveld, G.

Nieuwe boeken voor den nieuwen tijd. Uitgeverij De

Amsterdamsche Keurkamer, 1932-1944, Den Haag,

SDU, 1992. (P. Van HeEs)

LAROY, P.

"Aan de wieg van de Vlaamsche Beweeging..."

De geschiedenis van het Willemsfonds in Eeklo en

het Meetjesland, Gent, Liberaal Archief, 1993.

(N. Van Campenhout)

LiBOn, M.

Elie Baussart. "Raciner" les Wallons. Reeks Ecrits

politiques wallons, Charleroi, Institut Jules Destrée, 1993.

(P. GÉrin)

The Low Countries; Arts and Society in Flanders and the

Netherlands. A Yearbook 1994-95, Rekkem, Stichting

Ons Erfdeel, 1994. (L. Boeva)

Seberechts, F.

Ieder zijn zwarte. Verzet, collaboratie en repressie,

Leuven, Davidsfonds; Gent, Perspectief, 1994.

(G. De SMET) 
Swerts, E.

Mijn tienerjaren in oorlog en repressie, Kapellen,

Pelckmans, 1994. (G. De Smet)

256-259

Vandenpeereboom, A.

La fin d'un Règne. Notes et Souvenirs, Gent, Liberaal

Archief, 1994. (L. WILS)

263-264

Van De Woestijne, K.

- Verzameld journalistiek werk, deel 11, Nieuwe Rotterdamsche Courant, december 1921-december 1922, Gent, Cultureel Documentatiecentrum, 1993.

- Idem, deel 12, Nieuwe Rotterdamsche Courant, december 1922-juli 1924, Gent, Cultureel Documentatiecentrum, 1993.

- Idem, deel 13, Nieuwe Rotterdamsche Courant, juli 1924-augustus 1925, Gent, Cultureel Documentatiecentrum, 1994.

- Idem, deel 14, Nieuwe Rotterdamsche Courant, april 1925-november 1926, Gent, Cultureel Documentatiecentrum, 1994.

(P. Van Hees)

VAN ISACKER, K.

Irma Laplasse. Haar gevangenisdagboek. De kritiek op

haar strafdossier, Kapellen, Pelckmans, 1994 (3e druk).

(P. Van HeEs)

VAN Roy, L.

Brieven aan een kardinaal. Bijdrage tot de studie van de na-oorlogse periode, Wielsbeke, Oranje, 1994.

(G. De SMET)

256-259

Verreydt, D.

Meester Ernestine, Amsterdam, Nijgh en Van Ditmar;

Antwerpen, Dedalus, 1994. (P. Van Hees)

Verstraete, P.-J.

- Uit het dagboek van Hendrik Jozef Demoen, Kortrijk, in eigen beheer, 1993. (L. WiLs)

- Karel Dillen. Portret van een rebel. Bornem, Aksent, 1992. (G. De SMET)

25 jaar Rode Leeuwen. Een kwarteeuw Vlaams socialisme in de hoofdstad, Brussel, SP, 1993. (N. Van Campenhout) WARRIS, G.

Het bloedbad van Abbeville, 20 mei 1940, Antwerpen;

Baarn, Hadewych, 1994. (P. Van Hees) 